\title{
Perfil das atividades de vida diária dos atletas paraolímpicos de alta performance elaborado através do questionário HAQ (Health Assessment Questionnaire)
}

\author{
Antonia Jacimária Melo Carvalho ${ }^{\mathrm{a}}$, Alaine Aparecida Benetti de Grande ${ }^{\mathrm{b}}$ \\ aTerapeuta Ocupacional, Universidade Potiguar, Natal, RN, Brasil \\ ${ }^{\text {b}}$ Terapeuta Ocupacional, Mestre em Reabilitação Física, Universidade Federal de São Paulo - UNIFESP, \\ Docente, Curso de Terapia Ocupacional, Universidade Potiguar - UnP, Natal, RN, Brasil
}

\begin{abstract}
Resumo: O aumento da participação da pessoa com deficiência em atividades esportivas já é uma realidade, o esporte promove importante estímulo na reabilitação e reintegração à sociedade. A vida cotidiana de qualquer pessoa é composta por muitas Atividades de Vida Diária (AVD), se uma pessoa está inapta, poderá afetar os diversos papéis que possa vir a desempenhar. A Terapia Ocupacional tem como alvo principal, a intervenção na disfunção ocupacional. O objetivo desse estudo foi o de realizar um levantamento das principais dificuldades nas Atividades de Vida Diária dos atletas paraolímpicos com comprometimento motor, do projeto UNP/SUPERAR, através do protocolo HAQ (Health Assessment Questionnaire). Foi avaliado um total de 11 atletas paraolímpicos, todos medalhistas, com alto índice de performance em competições nacionais e internacionais e verificou-se que, apesar de serem campeões mundiais em suas categorias, existem dificuldades em realizar tarefas de vida diária básicas, assim como qualquer outra pessoa com deficiência, tornando necessária a intervenção da Terapia Ocupacional através do uso de recursos da Tecnologia Assistiva para essa população. Conclui-se que são necessários ainda estudos mais detalhados, aplicação de protocolos específicos a cada atleta, visando identificar outras tarefas que não estão descritas neste questionário.
\end{abstract}

Palavras-chave: Terapia Ocupacional, Medicina Esportiva, Reabilitação.

\section{Profile of activities of daily living of paralympians highperformance athletes prepared through questionnaire HAQ (Health Assessment Questionnaire)}

\begin{abstract}
The increased participation of the disabled in sports is already a reality. Sports promote an important stimulus in rehabilitation and reintegration in society. The daily life of any person is made up of many activities of daily living (ADLs). If a person is unsuitable, it may affect the various roles they might play. Intervention in occupational dysfunctions is the main target of Occupational Therapy. The present study aimed to survey the main difficulties in the Activities of Daily Living of Paralympians with motor impairment, from the UNP/SUPERAR project, through the HAQ (Health Assessment Questionnaire) protocol. A total of 11 Paralympic athletes, all medalists with high performance at national and international competitions, were assessed; it was found that, despite being world champions in their categories, they present difficulties in performing basic tasks of daily living, just like any other disabled person, requiring the intervention of occupational therapy through the use of Assistive Technology resources for this population. Further more detailed studies are needed, as well as the application of specific protocols for each athlete aiming to identify other tasks not described in this questionnaire.
\end{abstract}

Keywords: Occupational Therapy, Sports Medicine, Rehabilitation.

Autor para correspondência: Antonia Jacimária Melo Carvalho, Universidade Potiguar, Av. Senador Salgado Filho, 1610, Lagoa Nova, Natal, RN, Brasil, e-mail: jacimaria14@yahoo.com.br 


\section{Introdução}

A Organização Mundial de Saúde (OMS) calcula que entre $10 \%$ e $15 \%$ da população mundial (quase 1 bilhão de pessoas) sofre algum tipo de deficiência. No Brasil, o Censo de 2010 apontou que $6,7 \%$ da população se declararam com algum tipo de deficiência severa. Sendo deficiência motora com segundo maior porcentagem (INSTITUTO..., 2012)

$\mathrm{O}$ indivíduo com deficiência era considerado um peso para a sociedade, em função da condição física que o restringia, impedindo-o de desenvolver atividade rentável (FERNANDES, 2007, p. 896).

De acordo com Costa e Sousa (2004, p. 30), a história do desporto para as pessoas com necessidades especiais começou na cidade de Aylesbury na Inglaterra. A pedido do governo britânico, o neurologista Ludwig Guttmann criou o Centro Nacional de Lesionados Medulares do Hospital de StokeMandeville, destinado a tratar homens e mulheres do exército inglês, feridos na 2a Guerra Mundial, quando o contingente de pessoas com deficiência atingiu número considerável e os veteranos da segunda guerra foram recebidos como heróis, constatou-se a necessidade de buscar novas estratégias na assistência às pessoas com incapacidades. Nesse momento iniciava a alteração no enfoque voltado às pessoas com deficiência (FERNANDES, 2007, p. 896).

A introdução da terapia esportiva, assim como a posterior prática dos esportes adequados a cada paciente com pequenas e/ou grandes deficiências, as técnicas terapêuticas e os avanços tecnológicos, coube ao esporte nesses casos, importante estímulo na reabilitação e reintegração do deficiente à sociedade (VITAL et al., 2002)

A partir desse momento surgem duas correntes de pensamento, uma com enfoque médico, apresentada por Guttmann, que utiliza o esporte como auxílio na reabilitação de seus pacientes buscando amenizar também os problemas psicológicos advindos principalmente do ócio no hospital. $\mathrm{O}$ trabalho de reabilitação buscou no esporte não só o valor terapêutico, mas o poder de suscitar novas possibilidades, o que resultou em maior interaçáo dessas pessoas. Através do "esporte reabilitação" estava devolvendo à comunidade um deficiente, capaz de ser "eficiente" pelo menos no esporte. Ainda de acordo com Costa e Sousa (2004), outra corrente vinda dos Estados Unidos, utiliza o enfoque esportivo como forma de inserção social, dando a conotação competitiva utilizada pelo desporto. Essas correntes, no decorrer da história, cruzam-se formando objetivos comuns. Saindo do componente médico-terapêutico, estendem-se à incorporação da prática esportiva e do desporto de rendimento, procurando a integração do atleta e sua reabilitação social. Embora já se promovessem atividades esportivas para pessoas com deficiência, principalmente na Inglaterra, Estados Unidos e na Alemanha, foi em 1948 que este conceito ganhou caráter oficial, com a realização dos Jogos de StokeMandeville. Os médicos de Aylesbury começaram a adotar, definitivamente, a prática sistemática do esporte como parte essencial da reabilitação médica e social dos pacientes. Guttmann foi o precursor da reabilitação pelo esporte, das pessoas com deficiência.

O termo paraolímpico começou a ser usado em 1964, durante os jogos de Tóquio, com fusão das palavras paraplegia e olímpico. As modalidades fazem parte dos jogos, seja de participação individual, seja coletiva, são desportos de larga tradição competitiva, e coincidem com as modalidades olímpicas com as adaptaçôes necessárias para propiciar a prática pelos portadores de deficiência: atletismo, basquete em cadeira de rodas, judô para cegos, natação, vôlei sentado, tênis, tênis de mesa, futebol de sete, futebol de cegos, esgrima, ciclismo, halterofilismo, arco e flecha, hipismo e tiro olímpico. Bocha e goalball são de origem exclusivamente paraolímpica. A bocha foi criada exclusivamente para pessoas com paralisia cerebral e o goalball para deficientes visuais. (COSTA; SOUSA, 2004, p. 31).

No Brasil, o esporte adaptado foi introduzido logo após o surto de poliomielite, ocorrido na década de 1950. O desenvolvimento do esporte adaptado, nas últimas décadas, pode ser observado pelos inúmeros benefícios adquiridos através da sua prática, bem como pelo crescimento da Tecnologia Assistiva (FERNANDES, 2007).

Costa e Sousa (2004) diz que, atualmente, com a participação crescente do deficiente em atividades esportivas, foram criadas entidades de deficiências afins. Hoje as associaçôes que compóem o Comitê Paraolímpico Brasileiro são: Associação Brasileira de Desportos para Cegos (ABDC), Associação Brasileira de Desporto para Amputados (ABDA), Associação Brasileira de Desporto em Cadeiras de Rodas (Abradecar), Associação Nacional de Desporto para Excepcionais (Ande) e Associação Brasileira de Desportos para Deficientes Mentais (ABDEM), que programam, realizam e fomentam a iniciação e o desporto de alto rendimento para as respectivas áreas da deficiência.

O Comitê Paraolímpico Brasileiro (CPB), foi fundado no ano de 1995, como representante 
máximo do paradesporto nacional. A necessidade de se instituir o CPB deu-se em funçấo de uma exigência realizada pelo International Paraolympic Committee (IPC), estruturado a partir das Paraolimpíadas de Barcelona (1992), enquanto representante máximo do paradesporto mundial (RIBEIRO et al. 2004, p. 67).

Para Ribeiro et al. (2004), diante do aumento no número de participantes em algumas modalidades paradesportivas, atletas e técnicos sentiram a necessidade de criar as confederações, órgãos que respondem especificamente pelas modalidades paradesportivas, como é o caso da Confederação Brasileira de Basquetebol em Cadeira de Rodas (CBBC) em 1996, Confederação Brasileira de Tênis de Mesa Adaptado (CBTMA) e Confederação Brasileira de Dança em Cadeira de Rodas (CBDCR), ambas em 2001.

Outro órgão surge em decorrência da ampliação dos atendimentos voltados às pessoas com necessidades especiais, nos diversos segmentos como saúde, educação, esporte, entre outros, mas principalmente pela importância que representaria para o movimento uma entidade com o objetivo de facilitar o intercâmbio de informaçôes de caráter científico, além de valorizar os trabalhos desenvolvidos nas universidades. Em dezembro de 1994, profissionais como professores e/ou pesquisadores envolvidos há vários anos com a educação física e o esporte, fundaram a Sociedade Brasileira de Atividade Motora Adaptada (Sobama) (RIBEIRO et al., 2004).

Tais entidades têm como objetivo incentivar o esporte para pessoas portadoras de deficiência e organizar o desporto em nível de competiçóes regionais, nacionais e internacionais, organizando com o Comitê Paraolímpico Brasileiro a participaçáo das equipes nas Paraolimpíadas. O Brasil têm sido representado nas grandes competições internacionais. (COSTA; SOUSA, 2004, p. 35).

\section{Projeto UNP/SUPERAR}

O projeto "UNP/SUPERAR" resulta de uma construção coletiva dos professores das diversas áreas de atuação da Universidade Potiguar- UnP, e visa cumprir com responsabilidade os atendimentos aos atletas paraolímpicos pertencentes ao projeto SUPERAR, atletas estes, com alto índice de performance em competiçóes nacionais e internacionais. Outra perspectiva é propiciar à comunidade acadêmica, educação continuada, peça importante na integração entre as políticas acadêmicas de longo prazo, que buscam agregar as atividades de extensão às de graduação e pesquisa $\mathrm{O}$ grupo de professores/pesquisadores (doutores, mestres e especialistas) da UnP, conta com a participação de alunos das mais variadas áreas de formação dessa instituição de ensino superior, interessados neste estudo como trabalho interdisciplinar.Os tratamentos disponíveis visam aliviar os déficits e/ou as alteraçôes físicas, cognitivas e sociais através do uso de protocolos, melhorar a qualidade de vida do atleta com uma abordagem multidisciplinar e melhorar os índices de competição (UNIVERSIDADE..., 2009).

\section{Terapia ocupacional e Atividade de Vida Diária (AVD)}

A Terapia Ocupacional foi definida pela Associação Americana de Terapia Ocupacional (AOTA), em 1986, como

[...] a arte e a ciência que, por meio da aplicação de atividades cotidianas, incrementa a independência, possibilita o desenvolvimento e previne a doença, podendo utilizar adaptaçóes, nas tarefas ou no meio ambiente, para alcançar o máximo de independência e melhorar a qualidade de vida. (SANTOS, 2007, p. 775 apud FERNANDES, 2007).

O desempenho ocupacional é o campo de atuação da Terapia Ocupacional (PEDRETTI; EARLY, 2005).

Velloso e Jardim (2006), relata que as AVDs podem ser subdivididas em: AVDs básicas, que são todas aquelas feitas no cotidiano de forma automática e que todo ser humano realiza no decorrer do seu dia, como higiene pessoal, tomar banho, vestir-se, calçar-se e deambular; e AVDs instrumentais, que são aquelas atividades mais complexas de trabalho que necessitam maior independência funcional, como cozinhar, guardar utensílios em armários, arrumar a cozinha e lavar roupas.

A vida cotidiana de qualquer pessoa é composta por muitas atividades de vida diária e atividades instrumentais de vida diária que são desempenhadas em determinado contexto, que pode variar, incluindo o ambiente doméstico, escola, trabalho, hospital ou instituição. Se uma pessoa está inapta, temporariamente ou definitivamente, a fazer essas tarefas rotineiras de forma independente e eficiente em determinado contexto, segundo os padróes culturais de seu grupo social e seus valores pessoais, isso poderá afetar sua autoestima, horários, finanças, privacidade pessoal e os diversos papéis que possa vir a desempenhar (MELLO; MANCINI, 2007). 


\section{Objetivo}

O estudo teve o proposito de investigar as principais dificuldades nas Atividades de Vida Diária dos atletas paraolímpicos com comprometimento motor do projeto UNP/SUPERAR, através do protocolo HAQ (Health Assessment Questionnaire).

\section{Metodologia}

O estudo foi realizado na Escola de Saúde da Universidade Potiguar - UnP, localizada na cidade do Natal - RN, no período de fevereiro a maio de 2009.

Foram aplicadas as avaliaçóes que contaram com a identificação pessoal, modalidade desportiva, e aplicaçáo do HAQ (Health Assessment Questionnaire). Tal instrumento foi escolhido por ser um questionário de avaliação da saúde já validado no Brasil, que pode ser utilizado com a população adulta, indicado em caso de comprometimento motor (MELLO; MANCINI, 2007).

É um questionário auto aplicativo elaborado para avaliar qualidade de vida. Há dois tipos: HAQ forma completa e HAQ forma simplificada. Este último foi o escolhido por ser o mais utilizado na prática médica, sendo composto de 20 itens subdivididos em 8 categorias (vestir-se e arrumar-se; comer; andar; higiene pessoal; alcançar coisas; agarrar; atividades). Cada questáo varia de zero (sem comprometimento funcional) a três (tarefa incapacitante). Para calcular o valor de HAQ forma simplificada, soma-se a pontuação máxima de cada categoria. O valor obtido é, então, dividido por oito, obtendo-se pontuação que varia de zero a três. Quanto maior a pontuação, maior é o grau de comprometimento funcional do paciente. (SHINJO; GONÇALVES; GONÇALVES, 2006). O índice é calculado pela média dos escores dos 8 componentes, segundo Martinez (1998), visando colher dados para verificação das dificuldades encontradas nas atividades cotidianas.

O instrumento foi aplicado com 11 atletas paraolímpicos, com deficiências motoras, tais como Paralisia Cerebral, Polineuropatia Sensitivo Motora, Amputação de Membros Superiores, Amputação de Membros Inferiores, Lesão Medular, Sequela de Poliomielite, e Acondroplasia do Desenvolvimento. Todos assistidos no projeto UNP/SUPERAR, sendo 08 do sexo masculino e 03 do sexo feminino. Esta investigação desenvolveu-se conforme a metodologia de pesquisa qualitativa e quantitativa com abordagem exploratória. A aplicação do protocolo HAQ ocorreu na Clínica Escola do Curso de Terapia Ocupacional e as dificuldades ou não das Atividades de Vida
Diária foram levantadas através do HAQ (Health Assessment Questionnaire).

O presente estudo atendeu as determinaçôes da resoluçáo 196/96 do Conselho Nacional de Saúde. O projeto foi submetido ao Comitê de Ética em Pesquisa da Universidade Potiguar - UnP 037/2009. Somente foram admitidos no estudo os atletas paraolímpicos que concordaram com a metodologia descrita no Termo de Consentimento Livre e Esclarecido (TCLE).

\section{Resultados e discussão}

Neste estudo buscou-se realizar um levantamento das dificuldades nas atividades de vida diária de todos os atletas paraolímpicos, com deficiências motoras que fazem parte do projeto de extensão UNP/SUPERAR, através do questionário Health Assessment Questionnaire (HAQ).

A Terapia Ocupacional tem como alvo principal a intervenção na disfunção ocupacional. Esta é traduzida no cotidiano do indivíduo como uma dificuldade para realizar alguma atividade que lhe seja rotineira. Portanto um dos aspectos cruciais no processo terapêutico ocupacional é a Atividade de Vida Diária (MELLO; MANCINI, 2007).

A AOTA (American Occupational Therapy Association) identificou ocupação como "[...] as coisa comuns e familiares que as pessoas fazem todos os dias". A capacidade de buscar e realizar as ocupações habituais de uma pessoa é considerada normal enquanto a pessoa esta bem. Lesóes ou doenças podem perturbar as ocupações. (EARLY, 2005, p. 125).

Como descrito em Amiralian (2000), a deficiência é caracterizada pela perda ou anormalidade de estrutura ou função psicológica, fisiológica ou anatômica, temporária ou permanente. Incluem-se nessas a ocorrência de uma anomalia, defeito ou perda de um membro, órgão, tecido ou qualquer outra estrutura do corpo, inclusive das funçóes mentais. Já a incapacidade pela restrição, resultante de uma deficiência, da habilidade para desempenhar uma atividade considerada normal para o ser humano. Surge como consequência direta ou é resposta do indivíduo a uma deficiência psicológica, física, sensorial ou outra. Representa a objetivação da deficiência e reflete os distúrbios da própria pessoa, nas atividades e comportamentos essenciais à vida diária.

No presente trabalho foram avaliados $11(100 \%)$ atletas paraolímpicos pertencentes ao projeto de extensão UNP/SUPERAR. Destes, 8 (73\%) eram do sexo masculino e 3 (27\%) do sexo feminino, 
indicando maior prevalência do sexo masculino. Conforme Figura 1.

Com relação às modalidades praticadas, os achados foram: um (9\%) pratica atletismo; sete (64\%) praticam natação; um (9\%) pratica halterofilismo; um (9\%) pratica tênis de mesa; e um (9\%) pratica tiro com arco. O Figura 2 dispóe estes dados.

Quanto à deficiência e/ou diagnóstico obteve-se: uma (9\%) com paralisia cerebral; duas (18\%) com lesão medular; uma (9\%) com polineuropatia sensitivo motora; três (28\%) comseqüela de poliomielite; uma (9\%) com acondroplasia do desenvolvimento; uma (9\%) com amputação de membro superior (MMSS); duas (18\%) com amputação nos membros inferiores (MMII). O Figura 3 demonstra.

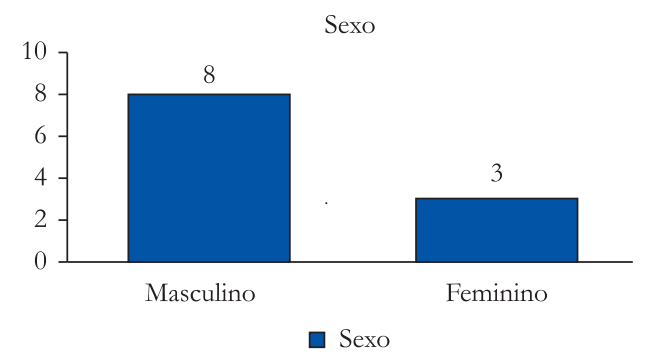

Figura 1. Quanto ao sexo dos atletas paraolímpicos.

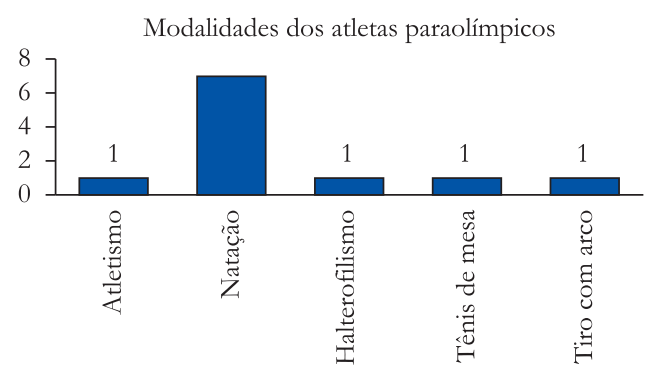

Figura 2. Modalidades dos atletas paraolímpicos.

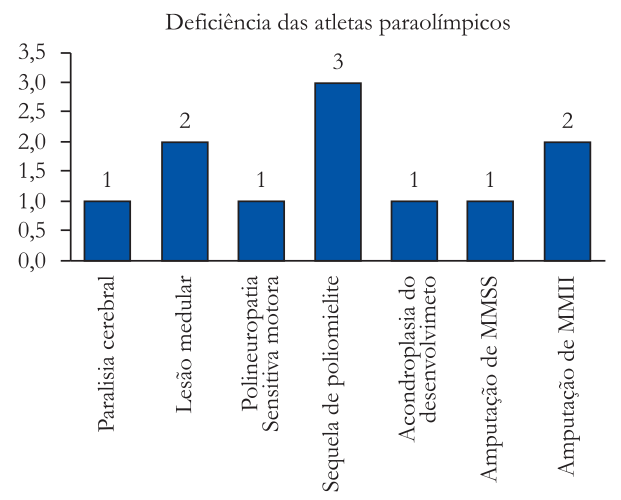

Figura 3. Deficiências e/ou diagnósticos dos atletas paraolímpicos.
De acordo com o questionário Health Assessment Questionnaire (HAQ) os escores totais apresentados pelos atletas paraolímpicos variaram com menor pontuação de 0,5 para maior de 2,75 . Conforme observamos no Figura 4. Considerando que quanto maior a pontuação, maior é o grau de comprometimento funcional.

As principais incapacidades apresentadas pelos atletas paraolímpicos de acordo com o questionário HAQ foram as atividades de segurar-se em pé no ônibus ou metrô, em 5 atletas, entrar e sair de um ônibus, em 4 atletas, fazer compras nas redondezas onde mora, em 3 atletas, cortar um pedaço de carne, em 3 atletas e levantar-se de maneira ereta de uma cadeira de encosto reto e sem braços em 3 atletas. Conforme Figura 5.

Tendo em vista as dificuldades apresentadas pelos atletas paraolímpicos descritas pelo questionário HAQ, faz-se necessário a intervenção da Terapia Ocupacional. Pois de acordo com o COFFITO (site, 2009) é função do terapeuta ocupacional operar com as capacidades de desempenho das Atividades de Vida Diária (AVDs) e Atividades

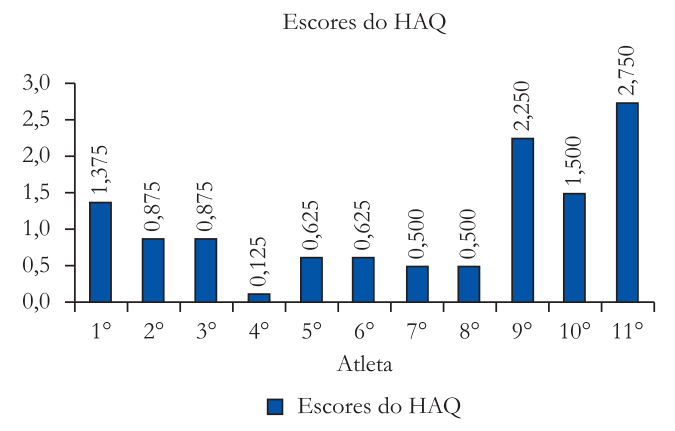

Figura 4. Escores do HAQ.

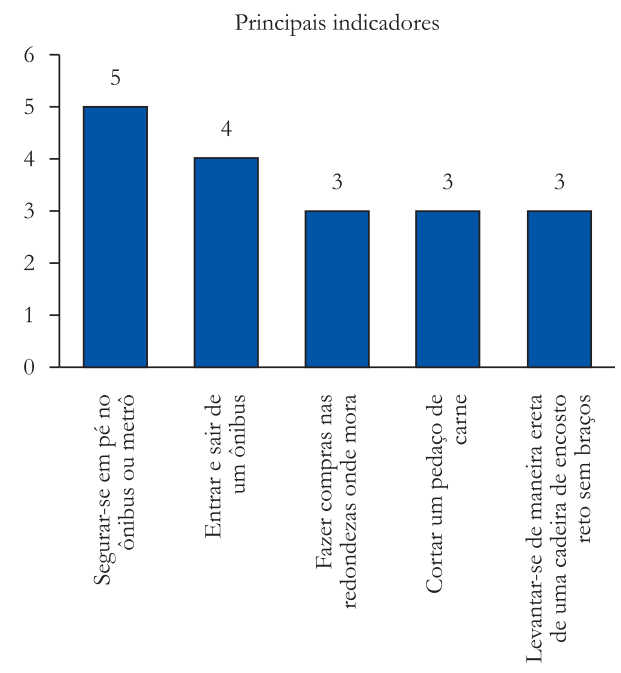

Figura 5. Principais incapacidades. 
Instrumentais de Vida Diária (AIVDs); compete ao mesmo identificar os problemas que interferem na independência do indivíduo, determinar objetivos de tratamento, proporcionar treinamento, assim como aplicar recursos da Tecnologia Assistiva, visando facilitar as tarefas cotidiana.

\section{Considerações finais}

Este estudo objetivou realizar um levantamento das principais dificuldades nas Atividades de Vida Diária dos atletas paraolímpicos com comprometimento motor do projeto UNP/SUPERAR, através do protocolo HAQ (Health Assessment Questionnaire), verificar a necessidade da intervenção do terapeuta ocupacional e de recursos da Tecnologia Assistiva para esta população.

Assim, em função do material e método adotado, percebe-se que os atletas paraolímpicos, mesmo com alto índice de performance em competiçôes e medalhistas nacionais e internacionais, apresentam dificuldades e/ou incapacidades de realizar algumas Atividades de Vida Diária descritas no questionário HAQ, porém são necessários ainda estudos mais detalhados ou até mesmo aplicação de outros questionários visando identificar outras tarefas que não estão descritas neste. Fica assim clara a necessidade de intervenção do terapeuta ocupacional para esta população.

\section{Referências}

AMIRALIAN, M. L. T et al. Conceituando deficiência. Revista de Saúde Pública, São Paulo, v. 34, n. 1, p. 97-103, fev. 2000. http://dx.doi.org/10.1590/ S0034-89102000000100017

COSTA, A. M.; SOUSA, S. B. Educação física e esporte adaptado: historia avanços e retrocessos em relação aos princípios da integração/inclusão e perspectivas para o século XXI. Revista Brasileira de Ciências do Esporte, Campinas, v. 25, n. 3, p. 27-42, maio 2004.

EARLY, M. B. Desempenho Ocupacional. In: PEDRETTI, L. W.; EARLY, M. B. Terapia Ocupacional: capacidades praticas para as disfunçóes físicas. 5. ed. São Paulo: Roca, 2005. p. 125.

FERNANDES, A. C. et al. AACD Medicina e Reabilitação: Princípios e Praticas. São Paulo: Artes Médicas, 2007.

INSTITUTO BRASILEIRO DE GEOGRAFIA E ESTATÍSTICA - IBGE. Censo 2010: País tem declínio de fecundidade e migração e aumentos na escolarização, ocupaçáo e posse de bens duráveis. Disponível em: $<$ http://www.ibge.gov.br/home/presidencia/noticias/ noticia_visualiza.php?id_noticia=2018 >. Acesso em: 10 fev. 2012, 09:35:00.

MARTINEZ J. E. et al. Análise critica de parâmetros de qualidade de vida de pacientes com fibromialgia. Acta Fisiátrica, São Paulo, v. 5, n. 2, p. 116-120, ago. 1998.

MELLO, M. A. F.; MANCINNI, M. C. Métodos e técnicas de avaliação nas áreas de desempenho ocupacional. In: CAVALCANTI, A.; GALVÃO, C. Terapia Ocupacional: fundamentação \& prática. Rio de Janeiro: Guanabara Koogan, 2007. p. 49-52.

PEDRETTI, L. W.; EARLY, M. B. Terapia Ocupacional: capacidades práticas para as disfunçôes físicas. 5. ed. São Paulo: Roca, 2005.

RIBEIRO, S. M. et al. A formaçáo acadêmica refletindo na expansão do desporto adaptado: uma abordagem brasileira. Revista Brasileira de Ciências do Esporte, Campinas, v. 25, n. 3, p. 57-69, maio 2004.

SHINJO S.; GONÇALVES, R.; GONÇALVES, C. Medidas de avaliaçáo clínica com espondilite anquilosante: revisão da literatura. Revista Brasileira de Reumatologia, Sáo Paulo, v. 46, n. 5, p. 340-346, set./out. 2006. http:// dx.doi.org/10.1590/S0482-50042006000500007

VELLOSO, M.; JARDIM, J. R. Funcionalidade do paciente com doença pulmonar obstrutiva crônica e técnicas de conservação de energia. Jornal Brasileiro de Pneumologia, São Paulo, v. 32, n. 6, p. 580-586, nov./ dez. 2006. Pmid:17435910. http://dx.doi.org/10.1590/ S1806-37132006000600017

VITAL, R. et al. Avaliaçáo clínica dos atletas Paraolímpicos. Revista Brasileira de Medicina do Esporte, São Paulo, v. 8, n. 3, p. 77-83, maio/jun. 2002.

UNIVERSIDADE POTIGUAR - UnP. Disponível em: <http://www.unp.br/jportal/portal.jsf?pagina=11265>. Acesso em: 30 maio 2009, 10:30:30.

\section{Contribuição dos Autores}

Antonia Jacimária Melo Carvalho: Autor. Alaine Aparecida Benetti de Grande: Autor/Orientador. 